\title{
Humidity effects on the detection of soluble and insoluble nanoparticles in butanol operated condensation particle counters
}

\author{
Christian Tauber $^{1}$, Sophia Brilke ${ }^{1}$, Peter Josef Wlasits ${ }^{1}$, Paulus Salomon Bauer ${ }^{1}$, Gerald Köberl ${ }^{1}$, \\ Gerhard Steiner $^{1,2,3}$, and Paul Martin Winkler ${ }^{1}$ \\ ${ }^{1}$ Faculty of Physics, University of Vienna, Boltzmanngasse 5, 1090 Vienna, Austria \\ ${ }^{2}$ Institute for Ion Physics and Applied Physics, University of Innsbruck, Technikerstraße 25/3, 6020 Innsbruck, Austria \\ ${ }^{3}$ Grimm Aerosol Technik Ainring GmbH \& Co. KG, Dorfstraße 9 Ainring, 83404 Ainring, Germany
}

Correspondence: Christian Tauber (christian.tauber@univie.ac.at)

Received: 18 January 2019 - Discussion started: 31 January 2019

Revised: 8 June 2019 - Accepted: 14 June 2019 - Published: 8 July 2019

\begin{abstract}
In this study the impact of humidity on heterogeneous nucleation of $n$-butanol onto hygroscopic and nonabsorbent charged and neutral particles was investigated using a fast expansion chamber and commercial continuous flow type condensation particle counters (CPCs). More specifically, we measured the activation probability of sodium chloride $(\mathrm{NaCl})$ and silver (Ag) nanoparticles by using $n$-butanol as condensing liquid with the size analyzing nuclei counter (SANC). In addition, the cutoff diameters of regular butanolbased CPCs for both seed materials under different charging states were measured and compared to SANC results. Our findings reveal a strong humidity dependence of $\mathrm{NaCl}$ particles in the sub-10 $\mathrm{nm}$ size range since the activation of sodium chloride seeds is enhanced with increasing relative humidity. In addition, negatively charged $\mathrm{NaCl}$ particles with a diameter below $3.5 \mathrm{~nm}$ reveal a charge-enhanced activation. For $\mathrm{Ag}$ seeds this humidity and charge dependence was not observed, underlining the importance of molecular interactions between seed and vapor molecules. Consequently, the cutoff diameter of a butanol-based CPC can be reduced significantly by increasing the relative humidity. This finding suggests that cutoff diameters of butanol CPCs under ambient conditions are likely smaller than corresponding cutoff diameters measured under clean (dry) laboratory conditions. At the same time, we caution that the humidity dependence may lead to wrong interpretations if the aerosol composition is not known.
\end{abstract}

\section{Introduction}

In the atmosphere nanoparticle formation by gas-to-particle conversion has been observed in a variety of locations and conditions (Kulmala et al., 2004). On a global scale, it is seen as an important source controlling the number size distribution of atmospheric aerosols (Kulmala et al., 2014). Thereby, a phase transition from the gaseous to the liquid or solid state occurs in the presence of supersaturated vapors. This process of nucleation arises homogeneously from gas molecules only or heterogeneously by the formation of vapor clusters on preexisting particles (Strey et al., 1986; Winkler et al., 2008b; Kangasluoma et al., 2016; Ferreiro et al., 2016; Tauber et al., 2018). These nanoparticles then can grow up to a size at which they act as cloud condensation nuclei (CCN) (Spracklen et al., 2008; Merikanto et al., 2009). Thereby nanometer-sized particles contribute to the indirect radiative forcing, thus influencing the Earth's climate (IPCC, 2013).

Heterogeneous nucleation in the atmosphere takes place for seed particles and vapor molecules of different chemical composition. Aerosol particles acting as seeds in the heterogeneous nucleation process have different physicochemical surface properties such as charging state, wettability, shape or size. Interactions between the seed and the vapor molecules as well as solubility play an important role (Kupc et al., 2013; McGraw et al., 2012, 2017). Atmospheric aerosol can contain hygroscopic salts and is therefore sensitive to relative humidity, which can contribute to a phase transition within the aerosol particle. 
A highly hygroscopic and well characterized example is sodium chloride $(\mathrm{NaCl})$, which mainly originates from sea spray (Biskos et al., 2006; Krämer et al., 2000; Clarke et al., 2003; Lawler et al., 2014; Zieger et al., 2017). Water vapor strongly influences the phase of the hygroscopic $\mathrm{NaCl}$ particles which under dry conditions exhibit a solid crystalline structure. At high relative humidity (RH), salt particles take up water and form saline droplets with increased volume, which affects their physical, chemical and optical properties. In contrast to increasing $\mathrm{RH}$, aqueous saline aerosol particles shrink with decreasing relative humidity. Thereby the water evaporates and the seed crystalizes (Martin, 2000; Biskos et al., 2006).

In a recently published paper by Tauber et al. (2018), it has been shown that the presence of monoatomic ions significantly lowers the energy barrier for the heterogeneous nucleation of $n$-butanol compared to neutral seeds. It is known from previous studies that ion-induced nucleation is highly affected by the chemical structure of the condensing vapor and seed ion properties like charge state (Iida et al., 2009; Kangasluoma et al., 2016). This process comes into play especially in the sub- $3 \mathrm{~nm}$ size range at which condensationbased nanoparticle detection methods have their lower detection limit. Thereby the initial charge state of aerosol particles with diameters within this size range can influence the detection efficiency.

In the atmosphere usually more than a single species of vapor molecules contributes to the vapor-liquid nucleation. Both processes, gas-to-particle conversion and the existence of insoluble particles in the atmosphere, can initiate heterogeneous nucleation processes (Kulmala et al., 2004; McMurry et al., 2005; Kuang et al., 2010, 2012; Wang et al., 2013). A commonly used technique to measure preexisting particles in the atmosphere is condensation particle counting, which often uses $n$-butanol as a working fluid (McMurry, 2000). However, under ambient conditions significant amounts of water vapor usually enter the condensation particle counter (CPC) and can modify its detection behavior. Previous studies on binary heterogeneous nucleation of $n$ propanol-water-vapor mixtures on sodium chloride $(\mathrm{NaCl})$ particles indicated a decrease in the activation barrier in accordance with the theory of binary heterogeneous nucleation and reported a soluble-insoluble transition in the particle activation behavior (Petersen et al., 2001). Butanol is chemically similar to propanol and commonly used as a working fluid in CPCs. Therefore the process of heterogeneous nucleation of $n$-butanol and water vapor on nanometer-sized particles is of high relevance in ambient nanoparticle characterization studies. In addition, pulse height analysis conducted by Hanson et al. (2002) for sulfuric acid particles revealed a strong dependence of the particle counter's response on chemical composition and water vapor. The size-resolved chemical composition measurements of nanoparticles from reactions of sulfuric acid with ammonia and dimethylamine, investigated by Chen et al. (2018), suggest that small, acidic and newly formed particles can affect the physicochemical properties during the cluster formation process and thereby enhance early particle growth. This indicates a chemical cluster composition and working-fluid-dependent activation behavior at the lower detection limit of the used CPC.

Over the last years various studies investigated the onset saturation ratio and the nucleation temperature for different seeds and vapors. These studies include measurements by Chen and $\mathrm{Tao}(2000)$ for water on $\mathrm{SiO} 2$ and $\mathrm{TiO} 2$ and by Schobesberger et al. (2010) for $n$-propanol on silver (Ag) and sodium chloride seeds. All studies show that the expected temperature trend agrees with theory, except for the nucleation of $n$-propanol on $\mathrm{NaCl}$ particles. In this specific case an opposite temperature trend of the onset saturation ratio compared to the Kelvin equation in the temperature range from 262 to $287 \mathrm{~K}$ was recorded (Schobesberger et al., 2010). Despite the common use of butanol as a working fluid for the detection of ambient nanoparticles, comparatively little research on the fundamental aspects of butanol nucleation has been done in the sub-10 nm size range (e.g., Barmpounis et al., 2018; Sem, 2002). For diethylene glycol (DEG)-based CPCs Iida et al. (2009) and Kangasluoma et al. (2013) investigated the temperature and humidity dependence of the working fluid on the particle activation. Here, we investigate heterogeneous nucleation of $n$-butanol vapor on differently sized seeds in the sub-10 nm diameter range depending on relative humidity, charge state and nucleation temperature. We aim at getting a better understanding of the effect of RH and initial charging states on the nucleation process in CPCs with the focus on sub- $5 \mathrm{~nm}$ particles. Thereby the relative humidity effect and charge dependence on the lower particle detection limit can be analyzed. The results help to improve the understanding of heterogeneous nucleation of $n$-butanol vapor on soluble and insoluble seeds. By that the acting mechanism during the nucleation process can be analyzed and used to explain changes in the counting efficiencies in commercial CPCs (Ankilov et al., 2002).

\section{Experimental section}

We examined the nucleation probability and counting efficiency of $n$-butanol-based CPCs as shown schematically in Fig. 1 and Fig. S1 in the Supplement. $\mathrm{Ag}$ and $\mathrm{NaCl}$ particles were generated in a tube furnace (Scheibel and Porstendörfer, 1983) which was supplied with synthetic air (ALPHAGAZ 1 AIR, $>=99.999 \%$ (5.0), Air Liquide) or particle-free dry compressed air. The flow carrying the polydisperse aerosol was kept constant at $3 \mathrm{~L} \mathrm{~min}^{-1}$ through the Americium 241 (Am-241) charger and the nanodifferential mobility analyzer (nDMA) for both experimental approaches. By applying positive or negative voltage to the nDMA, a monodisperse negatively or positively charged particle fraction was selected. By placing an Am-241 charger either at the size analyzing nuclei counter (SANC) or the 
CPC inlet, the size-selected particles were neutralized. Subsequently, ions that form inside the charger were removed using a home-built ion precipitator (ion trap). By applying a voltage of $\pm 500 \mathrm{~V}$ to a tubing which is cut in two halfpipes and separated by a nonconductive material, all charger ions were removed. An adjustable well-defined flow of humid air joined the aerosol flow after the nDMA in order to vary the humidity before the CPC inlet flow. Accordingly, the carrier gas was humidified by passing it through a diffusion type humidifier (see Fig. 1). The relative humidity of the carrier gas was monitored and recorded throughout every measurement. The recorded RH values were stable within $\pm 1 \%$, which is below the sensor accuracy. Two humidity sensors (HIH-4000-004, Honeywell) monitored the humidity of the aerosol flow before and after the injection of the humid flow. The amount of water vapor during the counting efficiency measurements was kept constant. Diffusional particle losses were kept to a minimum by keeping tubing as short as possible. In every measurement sequence, particle tubing to the CPC and Faraday cup electrometer (FCE) was kept to the same length. In addition, the flow rates were kept constant and the flow was symmetrically split. The additional particle losses for the neutral experiments were calculated following Tauber et al. (2019).

Measurements of heterogeneous nucleation of $n$-butanol at nucleation temperatures ranging from 270 to $292 \mathrm{~K}$ were carried out with the SANC (Wagner et al., 2003). To this end, monodisperse particle fractions were mixed with a carrier gas flow of $5 \mathrm{~L} \mathrm{~min}^{-1}$ containing $n$-butanol vapor and led into the expansion chamber of the SANC. $n$-Butanol vapor was added to the system by controlled injection using a syringe pump, followed by quantitative evaporation of the liquid beam in a heating unit (Winkler et al., 2008a). As a result, the well-defined and nearly saturated binary vapor-air mixture together with size-selected, neutralized monodisperse seed particles from the nDMA was passed into the temperaturecontrolled expansion chamber. Vapor supersaturation was achieved by adiabatic expansion, and the number concentration of droplets nucleating on the seeds was measured with the constant-angle Mie scattering (CAMS) method (Wagner, 1985). Based on the CAMS method a one-to-one correlation between the time-dependent measured scattered light flux under a constant angle and the calculated scattered light flux as a function of droplet size can be established. Thus, the radius and the number concentration of the growing droplets could be determined simultaneously. This allows us to determine the growth curve of the growing droplets which can be compared to theoretical calculations from a condensation model. Thereby, the saturation ratio can be verified with an accuracy of $2 \%-3 \%$. By varying the chamber temperature and the pressure drop in the expansion chamber, different nucleation conditions were analyzed. The nucleation or activation probabilities were measured with the SANC/CAMS method (Wagner et al., 2003). To evaluate the onset saturation ratio, which corresponds to a nucleation probability
Table 1. Temperature settings of the three TSI 3776 UCPCs used in this study in parallel.

\begin{tabular}{lrrr}
\hline Settings & $\begin{array}{r}\text { Low } T \\
\left({ }^{\circ} \mathrm{C}\right)\end{array}$ & $\begin{array}{r}\text { Standard } T \\
\left({ }^{\circ} \mathrm{C}\right)\end{array}$ & $\begin{array}{r}\text { High } T \\
\left({ }^{\circ} \mathrm{C}\right)\end{array}$ \\
\hline Condenser & 1.1 & 10.0 & 18.9 \\
Saturator & 30.1 & 39.0 & 47.9 \\
Optics & 31.1 & 40.0 & 48.9 \\
\hline
\end{tabular}

value of $P=0.5$, the experimental data were fitted with a two-parameter fit function (Winkler et al., 2016).

In addition to the SANC measurements, the counting efficiencies of three ultrafine continuous flow type CPCs (model UCPC 3776, TSI Inc., Minneapolis, USA), whose temperature settings were changed over a range of $18^{\circ} \mathrm{C}$, were measured. In contrast to the SANC, the supersaturation is obtained by saturating a laminar flow and subsequently cooling the aerosol together with the saturated flow in the condenser. Both methods lead to heterogeneous nucleation and condensation of $n$-butanol vapor on the aerosol particles due to a temperature reduction. Thereby the particles grow to a size at which they can be detected optically. To measure the detection efficiency of the TSI UCPCs, the aerosol flow subsequent to size classification was symmetrically split. The aerosol was passed to three CPCs $\left(N_{\mathrm{CPC}, 1-3}\right)$, each operating at different temperature settings (see Table 1), and to the Faraday cup electrometer (FCE) $\left(N_{\mathrm{FCE}}\right)$, which was operated in parallel. Thereby the counting efficiency was determined relative to a FCE (model 3068B Aerosol Electrometer, TSI Inc., Minneapolis, USA). The detection efficiency $\eta$ of a UCPC can be determined by comparing the number concentration of the CPC $N_{\mathrm{CPC}, 1-3}$ and the total number concentration $N_{\mathrm{FCE}}$ according to the following relation:

$\eta=\frac{N_{\mathrm{CPC}, 1-3}}{N_{\mathrm{FCE}}}$.

In order to calculate the counting efficiency of the neutralized aerosol, we evaluated the charging efficiency and the theoretical penetration efficiency for the FCE and CPC to correct for the neutralization and penetration losses following Tauber et al. (2019). By operating the CPCs at different temperature settings we were able to analyze simultaneously the detection efficiency with varying peak super saturation ratios (Tauber et al., 2019). The particle detection efficiency mainly depends on the activation probability, which is primarily a function of supersaturation and particle diameter (Barmpounis et al., 2018). By conducting detection efficiency measurements, the cutoff diameter is determined. The cutoff diameter corresponds to the mobility diameter at which $50 \%$ of the particles are counted in a CPC. 


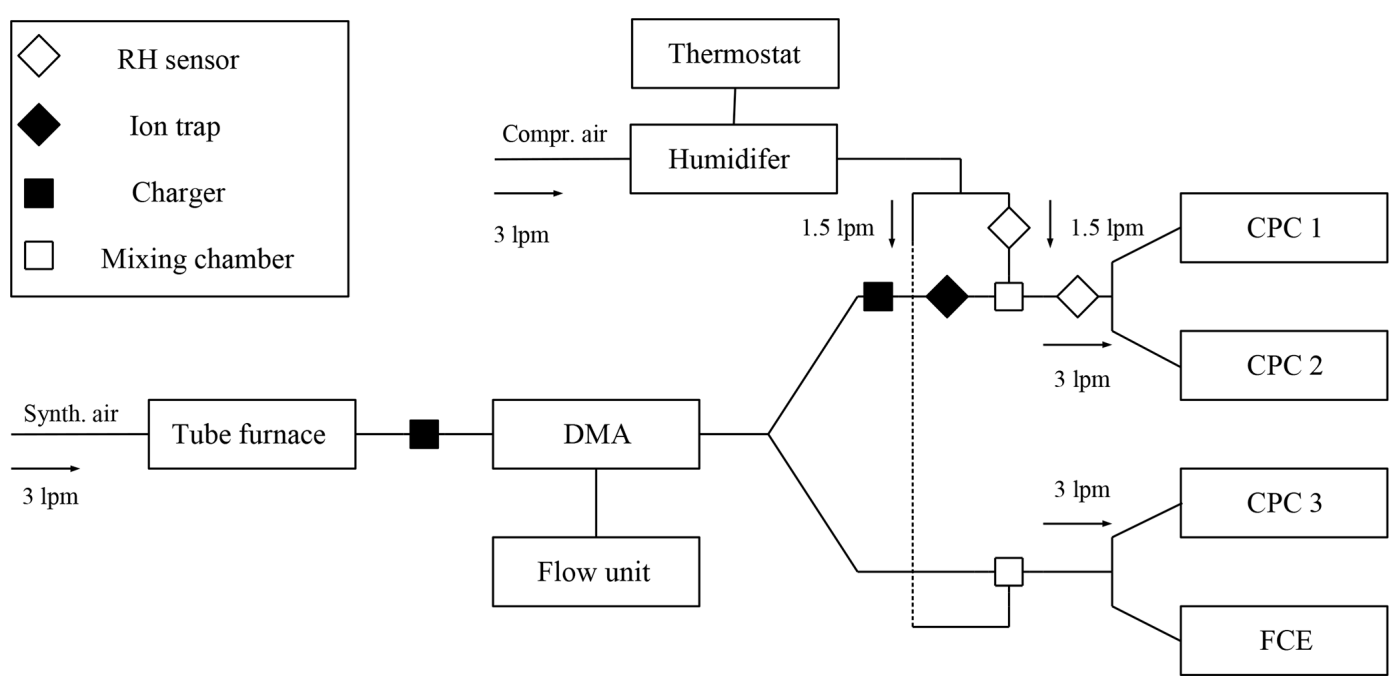

Figure 1. The experimental setup for evaluating the relative-humidity-dependent counting efficiency of continuous flow type CPCs (TSI 3776 UCPC), which was measured relative to a Faraday cup electrometer (FCE) (Wlasits, 2019).

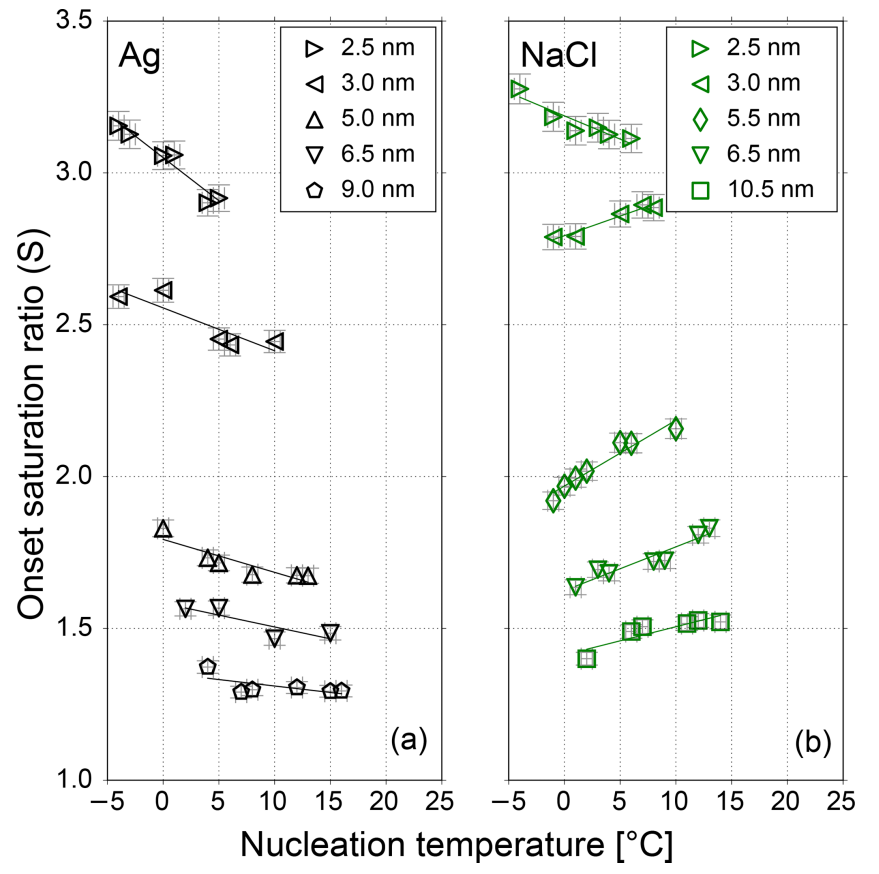

Figure 2. The onset saturation ratio versus nucleation temperature for neutral $\mathrm{Ag}$ (black) and $\mathrm{NaCl}$ (green) particles of different mobility equivalent diameters. With decreasing temperature the onset saturation ratio decreases for sodium chloride and increases for silver nanometer-sized particles. Only the $2.5 \mathrm{~nm} \mathrm{NaCl}$ seeds do not follow the opposite temperature trend. Lines represent a linear fit of data to show the temperature dependence for $\mathrm{NaCl}$ and $\mathrm{Ag}$ seeds. The onset saturation ratio increases with decreasing seed size for both test aerosols.

\section{Results and discussion}

\subsection{Temperature and humidity effects}

In this chapter we discuss the measurements of the onset saturation ratio of $n$-butanol depending on nucleation temperature and humidity with the SANC. The heterogeneous nucleation probability $(P)$ for different seeds and seed properties in the size range of 2.5 to $10.5 \mathrm{~nm}$ mobility diameter was investigated. The heterogeneous nucleation probability represents the number concentration of activated seeds normalized to the total number concentration of the aerosol. It depends on the saturation ratio which is given by the ratio of partial vapor pressure divided by the equilibrium vapor pressure at the corresponding temperature after expansion (nucleation temperature $T_{\text {nuc }}$ ). Measurements were conducted at constant $T_{\text {nuc }}$ by varying the vapor amount and keeping the pressure drop constant. In a recent study we have shown that with reduced nucleation temperatures the onset saturation ratio needed to activate a certain Ag particle size increases (Tauber et al., 2019). This is in line with classic Kelvin predictions (Thomson, 1871), where with decreasing temperature the required equilibrium saturation ratio increases. This behavior agrees with homogenous nucleation. To investigate the impact of $\mathrm{RH}$ on heterogeneous nucleation probability the $\mathrm{Ag}$ measurements were complemented by $\mathrm{NaCl}$ seeds. The resulting onset saturation ratios depending on the nucleation temperatures are shown in Fig. 2. Clearly, the required saturation ratio to activate a certain particle size is always lower for $\mathrm{Ag}$ particles compared to $\mathrm{NaCl}$ particles. Heterogeneous nucleation of $n$-butanol vapor on $\mathrm{NaCl}$ and $\mathrm{Ag}$ aerosol particles shows a remarkably different behavior. An opposite temperature trend for $\mathrm{NaCl}$ seeds was identified when compared to the Kelvin prediction, except for the smallest sodium 


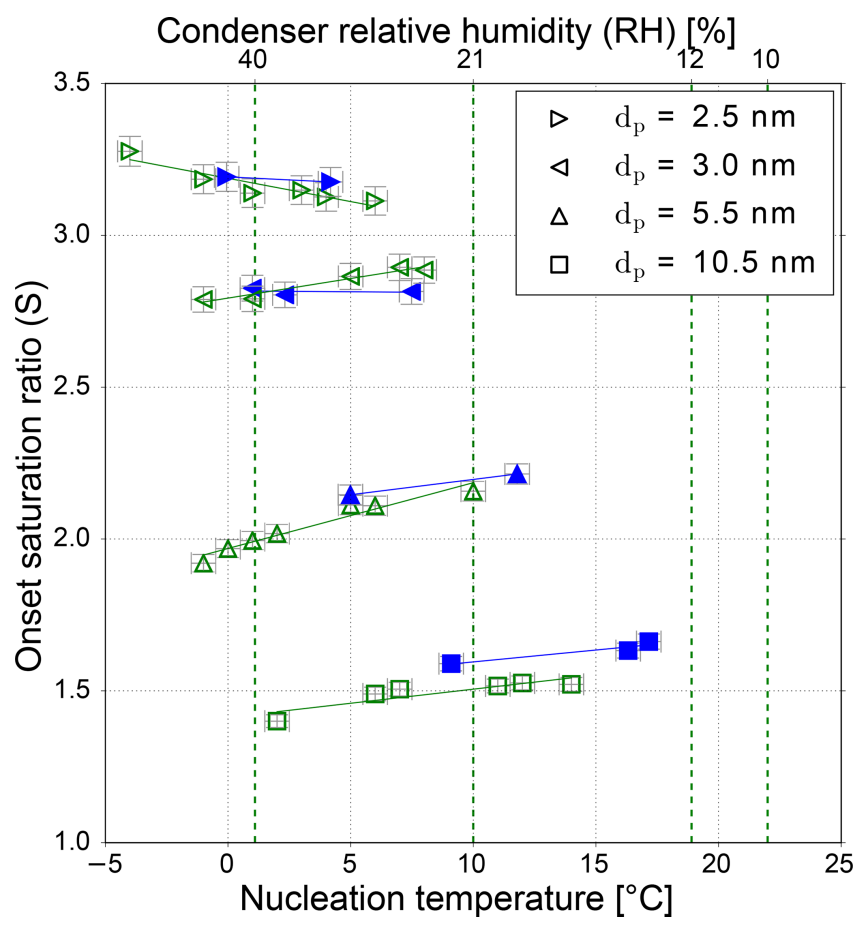

Figure 3. The onset saturation ratio versus nucleation temperature for $\mathrm{NaCl}$ particles of different mobility equivalent diameters. The green symbols show the onset saturation values recorded with relative humidity values $\leq 10 \%$, and the blue symbols represent measurement values when the RH was $<3.5 \%$. The green dashed vertical lines represent the calculated relative humidities at the corresponding preset condenser temperature (see Table 1 ) with a starting value of $10 \% \mathrm{RH}$ at $22^{\circ} \mathrm{C}$. The increased relative humidity inside the condenser of a TSI 3776 UCPC for reduced nucleation temperatures is shown and will be discussed in the counting efficiency measurements section.

chloride particles with a mobility diameter of $2.5 \mathrm{~nm}$. Such a trend was not found for silver nanoparticles.

This finding is consistent with already published results from Schobesberger et al. (2010) for $n$-propanol, where an opposite temperature trend for $\mathrm{NaCl}$ but not for $\mathrm{Ag}$ seeds could be observed. To rule out any humidity effects, the sheath air of the nDMA was monitored using a commercial relative humidity sensor during the measurements. Thereby an accumulation of water in the used silica gel dryer of the sheath air loop could be recorded. The water aggregation in the dryer, originating from the compressed air supply, reached values up to $10 \% \mathrm{RH}$ at $22^{\circ} \mathrm{C}$ room temperature. As a consequence, the carrier gas supplement for the experiment was changed from dried and filtered compressed air to synthetic air. Additional measurements were performed with a relative humidity $<3.5 \%$ at room temperature.

In Fig. 3 the experimental values for neutral sodium chloride seeds are shown and listed in Tables S5-S9 of the Supplement for both considered aerosol species. The necessary onset saturation ratio for activating dry particles of a cer- tain size is at the same value as high RH values $(<10 \%)$ or (with one exception) increased for dry measurements $(\mathrm{RH}<$ $3.5 \%$ ). In other words, the additional small amount of water vapor during the measurements decreases the energy barrier which has to be overcome to activate a sodium chloride nanoparticle with $n$-butanol in the observed size range. This finding suggests that even small contaminations of water vapor can influence the heterogeneous nucleation of butanol, a finding that agrees with already published studies for $n$ propanol-water mixtures on $\mathrm{Ag}$ and $\mathrm{NaCl}$ particles (Wagner et al., 2003).

For the heterogeneous nucleation of $n$-butanol on silver seeds, no decrease in the onset saturation ratio due to the presence of water was observed. The opposite temperature dependence for $\mathrm{NaCl}$ and synthetic air as carrier gas (blue symbols in Fig. 3) vanishes for small mobility diameters $(<3.5 \mathrm{~nm})$, but particle sizes above $3.5 \mathrm{~nm}$ still follow the unusual temperature dependence. This indicates that sodium chloride particles act differently in the observed size range. It seems that $\mathrm{NaCl}$ seeds at sizes below $\sim 3.5 \mathrm{~nm}$ are less prone to dissolution or restructuring effects. As a result, the nucleation of $n$-butanol on small $\mathrm{NaCl}$ seeds is comparable to silver clusters. The opposite temperature trend vanishes and follows the Kelvin relation. Another remaining question is the following: does the charge sign have an effect on heterogeneous nucleation? To answer this question, additional measurements focusing on charge and humidity for $\mathrm{NaCl}$ particles in the corresponding nanometer range were conducted.

\subsection{The influence of charge and particle restructuring effects}

To investigate the charge effect on heterogeneous nucleation of $n$-butanol vapor on silver and sodium chloride particles, the neutralizer and ion trap in front of the expansion chamber (see Fig. S1) were removed. Thereby the seeds were positively or negatively charged, depending on the applied voltage to the nDMA. Nucleation studies were conducted with constant nucleation temperatures but varying charge state of the aerosol using synthetic air as carrier gas. For positively charged silver particles no charge dependence on heterogeneous nucleation was found. However, $\mathrm{NaCl}$ seeds show a charge dependence, especially below $5 \mathrm{~nm}$. As listed in Table 2 the necessary onset saturation ratio for neutral and positively charged silver particles is below the $\mathrm{NaCl}$ values, and no charge enhancement was found. Negatively charged $\mathrm{Ag}$ particles could not be fully investigated due to technical problems with the SANC at the end of the measurement run. Kangasluoma et al. (2016) conducted measurements using tungsten oxide, ammonium sulfate and tetraheptylammonium bromide nanoclusters of different charge states to determine the counting efficiency. During their studies a chargeenhanced particle activation was observed similar to our findings regarding the $\mathrm{NaCl}$ measurements. 
Table 2. SANC experimental results for the onset saturation ratio for neutral $(n)$, positively $(+)$ and negatively $(-)$ charged particles. $D_{\mathrm{p}}$ is the mean mobility equivalent diameter, $\sigma_{\mathrm{g}}$ the mean geometric standard deviation and $S_{\text {onset }}$ the onset saturation ratio.

\begin{tabular}{lrrrr|rrr}
\hline & & \multicolumn{3}{c|}{$\mathrm{Ag}(\mathrm{RH}<2.5 \%)$} & \multicolumn{3}{c}{$\mathrm{NaCl}(\mathrm{RH}<2.5 \%)$} \\
\cline { 2 - 8 }$D_{\mathrm{p}}(\mathrm{nm})$ & $\sigma_{\mathrm{g}}$ & $\begin{array}{r}S_{\text {Onset }} \\
n\end{array}$ & $\begin{array}{r}S_{\text {Onset }} \\
+\end{array}$ & $\begin{array}{r}S_{\text {Onset }} \\
-\end{array}$ & $S_{\text {Onset }}$ & $S_{\text {Onset }}$ & $S_{\text {Onset }}$ \\
+ & - & - \\
\hline 2.5 & 1.073 & 3.10 & 3.07 & - & 3.19 & 3.20 & 3.04 \\
3.0 & 1.070 & 2.48 & 2.48 & - & 2.81 & 2.72 & 2.64 \\
3.5 & 1.067 & 2.33 & 2.33 & - & 2.60 & 2.54 & 2.47 \\
5.5 & 1.065 & 1.85 & 1.85 & 1.83 & 2.21 & - & 2.20 \\
9.0 & 1.068 & 1.34 & 1.36 & - & - & - & - \\
10.5 & 1.067 & - & - & - & 1.64 & 1.66 & 1.63 \\
\hline
\end{tabular}

It is known from prior research that $\mathrm{NaCl}$ aerosol particles, which are generated by evaporation and condensation in a tube furnace, undergo a structural change in the presence of water (Krämer et al., 2000; Biskos et al., 2006) or $n$-propanol (Petersen et al., 2001; Kulmala et al., 2001). As a consequence, the particles shrink in the presence of polar vapors. In order to test a humidity-induced change in particle size, we used a standard DMPS setup, which has a filtered and dried (using Silica gel) sheath air loop. The corresponding setup schema can be found in the supporting information (Fig. S3). Our results confirmed the measurements conducted by Biskos et al. (2006), showing the shrinkage of sodium chloride particles in the presence of water vapor. This shrinkage was also investigated in our study for $n$-butanol. The experimental results for water are shown in Fig. 4. We measured monodisperse $\mathrm{NaCl}$ aerosols with mobility diameters between 4.5 and $11 \mathrm{~nm}$ at relative humidities up to $50 \%$. The shrinkage measurements in Fig. 4 were conducted with SHT75 sensors, with an accuracy of $\pm 1.8 \% \mathrm{RH}$, and with a HMI38 Humidity Data Processor with a HMP35E probe, with an accuracy of $\pm 2.0 \%$ RH. However, with decreasing mobility diameter, the shrinkage also decreases. For example, an $11 \mathrm{~nm} \mathrm{NaCl}$ particle exposed to $40 \% \mathrm{RH}$ shrinks by about $15 \%$. A $4.5 \mathrm{~nm}$ particle at $40 \% \mathrm{RH}$ shrinks only by about $3 \%$. Hence, the structural rearrangement of particles below $5 \mathrm{~nm}$ is not as pronounced as for larger ones. This decrease in size for particles $>5 \mathrm{~nm}$ is a result of solvation on the surface of the $\mathrm{NaCl}$ particle caused by the presence of water vapor. Thereby a wet surface accrues (Castarède and Thomson, 2018). Due to this dissociation process and the resulting liquid surface, the particle attracts more polar vapor molecules. In addition, the overall polarity of the working fluid of $n$-butanol and water mixture increases, due to the higher dipole moment of water $\left(6.2 \times 10^{-30} \mathrm{Cm}\right)$ compared to $n$-butanol $\left(5.8 \times 10^{-30} \mathrm{Cm}\right)$ (Reichardt and Welton, 2011). As a result, additional vapor molecules can more readily condense onto the seed aerosol. This mechanism could explain the resulting lower onset saturation ratio needed for $\mathrm{NaCl}$ seeds $\geq 3 \mathrm{~nm}$ as shown in Fig. 3 for lower nucleation temperatures. Consequently, by reducing the nucleation temper-

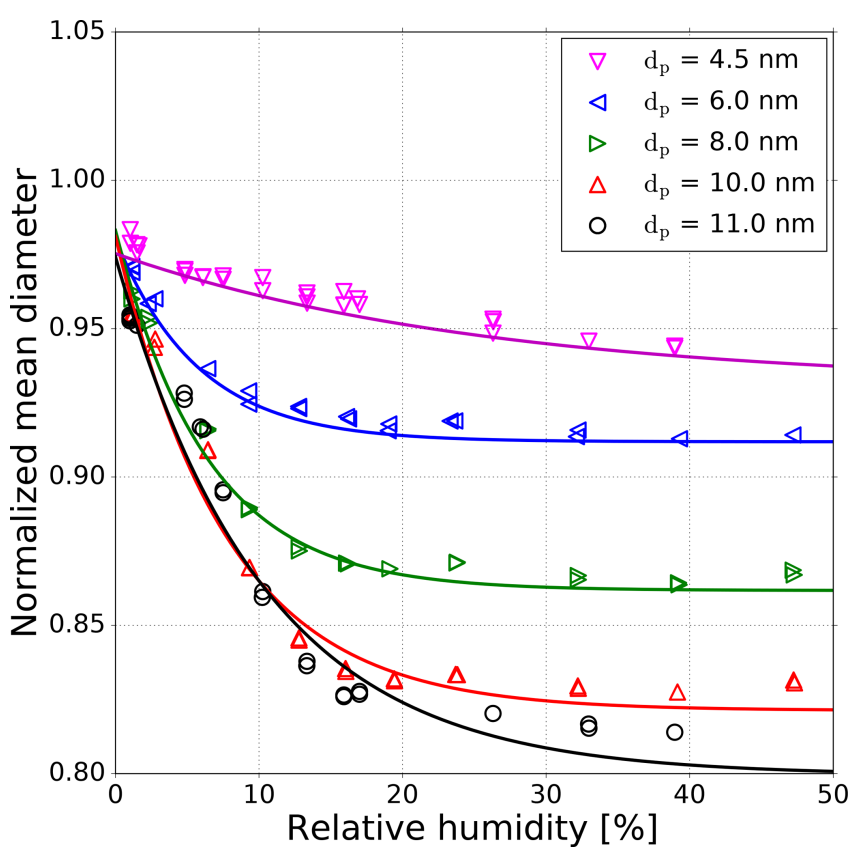

Figure 4. Normalized mean diameter of sodium chloride particles as a function of relative humidity which represents the shrinkage of $\mathrm{NaCl}$ seeds in the presence of water vapor. All sizes are mobility equivalent diameters. Each line represents a tentative threeparameter fit of an exponential decay. The measurements were conducted with SHT75 sensors with an accuracy of $\pm 1.8 \% \mathrm{RH}$ and with a HMP35E probe with an accuracy of $\pm 2.0 \% \mathrm{RH}$.

ature the saturation vapor pressure decreases, leading to an increase in the saturation ratio for water (RH is increasing; see Fig. 3, upper $x$ axis).

In summary, the SANC measurements allowed us to study the heterogeneous nucleation of $n$-butanol depending on the charge state, nucleation temperature and humidity of the carrier gas. Charge-enhanced nucleation could be found for sodium chloride particles $\leq 3.5 \mathrm{~nm}$. By taking special care of the water vapor amount a humidity-enhanced nucleation for sodium chloride seeds was found. Under dry conditions the observed opposite temperature trend for $\mathrm{NaCl}$ seeds 
$<3.5 \mathrm{~nm}$ vanishes. For larger sodium chloride particles this trend is found to be persistent.

\subsection{Counting efficiency measurements}

Complementing the SANC measurements, we have performed counting efficiency measurements at different condenser temperatures but constant $\Delta T$ between the saturator and condenser for a commercial $n$-butanol TSI 3776 UCPC. Thereby, we were able to increase or decrease the saturation ratio profile as described by Tauber et al. (2019). The onset saturation ratio and nucleation temperature measured with the SANC for a classified monodisperse seed particle size could be compared to the three different temperature settings of the condenser. The maximum value for the calculated saturation ratio profiles and the extrapolated $S_{\text {onset }}$ for $\mathrm{NaCl}$ (partly extrapolated from the lines in Figs. 2 and 3 ) under different humidity conditions at low, standard and high condenser temperatures are listed in Table 3 . Thus, the ability to activate sodium chloride seeds in the cutoff range of a commercial UCPC could be analyzed. With increasing temperature the maximum saturation ratio $(S)$ decreases. As a result, the detection efficiency shifts to larger particle sizes.

For the verification of our findings we measured the cutoff diameter, charge and relative humidity dependence for the TSI 3776 UCPC at different temperature settings. By varying the temperature settings of the UCPC we were also able to measure under different condenser (nucleation) temperatures (see Table 1). For comparison, particle classification with the nDMA was always performed under dry conditions $(\mathrm{RH}<3.5 \%)$ so that the structural change of the sodium chloride clusters resulting from water vapor is kept to a minimum. Subsequent to the size selection, the particles were mixed with humidified air to reach $\mathrm{RH}$ values ranging from 0 to $40 \%$ as shown in Fig. 1. Hence, we were able to vary the relative humidity with an accuracy of $\pm 3.5 \%$ by measuring the humidity before and after the mixing zone. In total, about 400 detection efficiency curves were recorded. To rule out any dependence of the individual activation behavior of different CPCs, measurements involving one single CPC set to all three temperature settings one after another and measurements involving three CPCs that were all set to one specific setting have been performed. Based on these measurements, the maximum error of the cutoff diameter linked to the individual activation behavior was calculated to be at its highest at $8.1 \%$. Results of earlier studies indicate a discrepancy of the humidity dependence for sodium chloride and silver nanoparticles on the detection efficiency of commercial CPCs (Sem, 2002). In the study conducted by Sem (2002), at increased RH the used CPCs had a lower cutoff diameter above $5 \mathrm{~nm}$. In this size range the particle shrinkage plays an important role: the already mentioned emerging liquid surface would attract further vapor molecules. Consequently, the $\mathrm{NaCl}$ particles can be more easily activated than an insoluble seed.

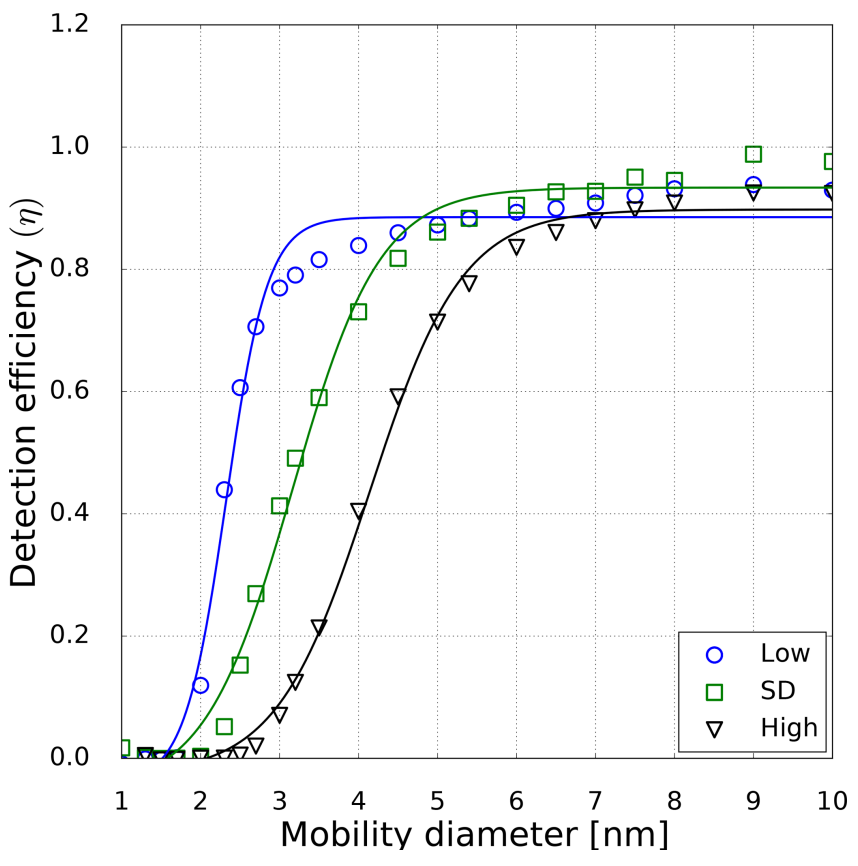

Figure 5. Detection efficiency as a function of mobility diameter for neutral sodium chloride particles. The symbols represent the measured counting efficiencies for low- (circles), standard- (std, squares) and high-temperature (triangles) settings at $10 \% \mathrm{RH}$ at room temperature of the inlet line. The line displays a fit to the measured counting efficiencies (Wiedensohler et al., 1997). Thereby the corresponding cutoff diameter with the detection efficiency of 0.5 can be evaluated.

However, in this study a TSI 3776 UCPC was used, which has a cutoff diameter well below $5 \mathrm{~nm}$. As an example, the detection efficiency measurement for the three CPC temperature settings is depicted in Fig. 5. These measurements were conducted under elevated humidity conditions $(\mathrm{RH}=10 \%$ at room temperature), which lead to a decrease compared to dry conditions $(\mathrm{RH}=3.5 \%)$ of the necessary onset saturation ratio for neutral $\mathrm{NaCl}$ seeds as shown in Fig. 3. Due to the temperature decrease in the condenser, the saturation ratio for water vapor increases up to $S=1.6$ with an inlet RH of $40 \%$ at room temperature. Studies conducted by Petersen et al. (2001) on binary heterogeneous nucleation of water$n$-propanol-vapor mixtures onto $\mathrm{NaCl}$ seeds also show that small amounts of water reduce the propanol activity substantially. Butanol is hardly miscible with water in macroscopic mixtures, but still small amounts support the nucleation. The resulting cutoff diameters for neutral, negatively and positively charged sodium chloride nanoparticles are shown in Fig. 6. It can be clearly seen that with increasing relative humidity the cutoff diameter decreases for a UCPC operating at standard conditions (green) from about 3.7 to about $2.0 \mathrm{~nm}$ for neutral $\mathrm{NaCl}$ clusters. To investigate a possible effect of the charge history of neutral particles, positively and negatively charged particles were neutralized. An effect 
Table 3. Calculated maxima of the CPC saturation ratio profiles $S_{\max }$ for low-, standard- and high-temperature settings (Tauber et al., 2019), in comparison to the extrapolated $S_{\text {onset }}$ as measured by the SANC.

\begin{tabular}{lrrrrr|rrrrr}
\hline & & \multicolumn{3}{c|}{$\mathrm{NaCl}$ neutral $(\mathrm{RH}<3.5 \%)$} & \multicolumn{4}{c}{$\mathrm{NaCl}$ neutral $(\mathrm{RH}<10.0 \%)$} \\
\cline { 3 - 9 }$d_{\mathrm{p}}(\mathrm{nm})$ & & 2.5 & 3.0 & 3.5 & 5.5 & 2.5 & 3.0 & 3.5 & 5.5 \\
\hline$T$ settings & $S_{\text {max }}$ & $S_{\text {onset }}$ & $S_{\text {onset }}$ & $S_{\text {onset }}$ & $S_{\text {Onset }}$ & $S_{\text {Onset }}$ & $S_{\text {onset }}$ & $S_{\text {onset }}$ & $S_{\text {onset }}$ \\
\hline Low & 4.3 & 3.18 & 2.81 & 2.65 & 2.10 & 3.17 & 2.80 & - & 1.99 \\
Standard & 3.4 & 3.15 & 2.81 & 2.57 & 2.20 & 3.03 & 2.92 & - & 2.18 \\
High & 2.8 & 3.11 & 2.80 & 2.50 & 2.28 & 2.90 & 3.03 & - & 2.37 \\
\hline
\end{tabular}

from charge history could possibly be that previously positively charged particles differ from those that were negatively charged prior to neutralization, e.g., by their original properties or because of a change in properties during the neutralization process (Kangasluoma et al., 2013; Alonso and Alguacil, 2008). The resulting cutoff diameters are shown in Fig. 6 (left). Regarding the charge history, no difference in activation could be found for sodium chloride. Only under high $n$-butanol saturation ratios (low temperature settings) and high-relative-humidity conditions, the previously negatively charged particles exhibit a lower cutoff diameter. In Fig. 6 (right panel), the cutoff diameters as a function of $\mathrm{RH}$ are shown for particles of different polarity. Remarkably, for charged $\mathrm{NaCl}$ particles we find increased cutoff diameters compared to the neutral particles. Since the flow carrying monodisperse aerosols and the flow of humid air are joined together in front of the CPC inlet, the increase in cutoff diameters could be a result of the increased attraction of water molecules to charged $\mathrm{NaCl}$ particles under subsaturated conditions. Thereby the $\mathrm{Na}^{+}$and $\mathrm{Cl}^{-}$ions get separated and form a solvent cage around themselves (Castarède and Thomson, 2018). This solvent cage reduces the tendency of ions to aggregate (Loudon, 2009).

$\mathrm{Li}$ and Hogan Jr. (2017) performed measurements on the uptake of organic vapor molecules by nanometer-scaled sodium chloride cluster ions, using a DMA coupled to a timeof-flight (TOF) mass spectrometer. The results show that the polarity and the molecular structure of the vapor molecules control the vapor uptake. This is in agreement with our findings: increasing amounts of water molecules are mixed with already preexisting butanol molecules. As a result, the overall bulk polarity of the working fluid increases and the activation of sodium chloride clusters is improved. In contrast to the SANC measurements, no significant sign preference for charge-enhanced nucleation could be found. This is probably due to the cutoff diameter size which is $>3 \mathrm{~nm}$ for most of the counters, except for negatively charged $\mathrm{NaCl}$ particles, which show a charge enhancement as it was observed with the SANC for particles with a mobility diameter $<3 \mathrm{~nm}$. In addition, the recorded cutoff diameter for high$T$ settings is in the size range, where the opposite temperature trend was recorded by the SANC measurements. Con-
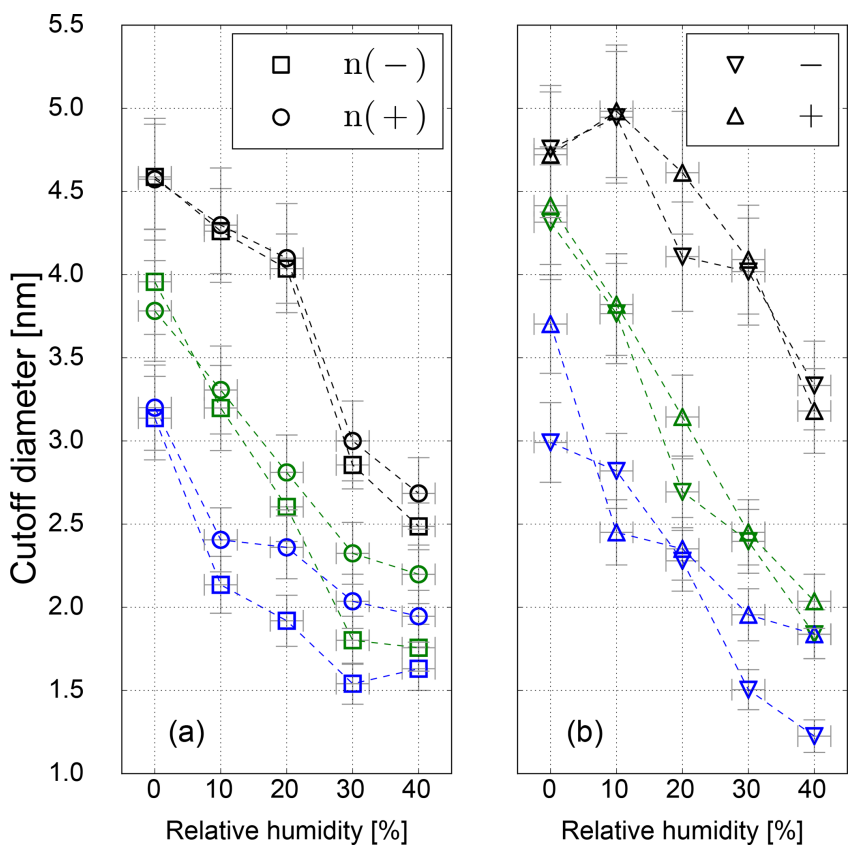

Figure 6. Cutoff diameter as a function of RH for neutral (a) and charged (b) sodium chloride seeds for low- (blue), standard- (green) and high-temperature (black) settings.

sequently, by decreasing the temperature the needed saturation ratio to activate a $\mathrm{NaCl}$ particle in this size range decreases. Furthermore, the increasing RH supports the structural rearrangement which reduces the cutoff diameter (see Fig. 6) compared to dry conditions. As stated in Castarède and Thomson (2018), the solvation of sodium chloride clusters leads to an electrical potential. In this study, we show that nucleation of $n$-butanol vapor onto soluble $\mathrm{NaCl}$ below $3.5 \mathrm{~nm}$ is enhanced. This effect takes place as the aerosol is exposed to RH, i.e., before the sample enters the CPC. Subsequently, inside the CPC, the RH increases due to the temperature reduction inside the condenser, which will have an effect on the charge enhancement. As a matter of fact, our results lead to an improved detection efficiency for sodium chloride clusters. At high relative humidity and low temperature settings the detection efficiency is further promoted by charge-enhanced nucleation. 
Results on the cutoff diameter depending on the relative humidity at the UCPC inlet for neutralized and charged silver seeds are shown in Fig. 7. For Ag particles no shrinkage in mobility diameter could be measured, and the clusters at a certain size can be assumed to be spherical (Winkler et al., 2016). As we can see in Fig. 7, no relative humidity dependence on the cutoff diameter within the uncertainty range was observed.

However, for charged particles we see slightly reduced cutoff diameters compared to neutral particles indicating charge-enhanced nucleation. While this finding is in line with previous work (Winkler et al., 2008b), the significant difference between neutral and charged particles especially at the higher temperature settings is likely a consequence of insufficient maximum saturation ratio to activate neutral particles of the same size. The calculated value of $S_{\max }$ at hightemperature settings of 2.8 (see Table 3) would be sufficient to activate particles of $2.8 \mathrm{~nm}$ according to the SANC measurements (Table 2 and Fig. 2). It should be noted though that in the CPC the region of $S_{\max }$ is limited to the center line, and most particles traveling outside this region will experience lower saturation ratios resulting in increased cutoff diameters. Overall, the charge enhancement seems to be weak both in the SANC measurements and the CPC settings. A sign preference becomes visible favoring the activation of negatively charged particles only at the lowest temperature settings. As expected, this sign preference vanishes for higher temperature settings (lower saturation ratios), which is in agreement with Winkler et al. (2008b).

In general, particle counting at the detection limit of ultrafine condensation particle counters has to be treated with care. The lowest detectable particle size, i.e., the cutoff diameter of a CPC, is among the largest sources of inaccuracy in the sub- $10 \mathrm{~nm}$ particle concentration measurement (Kangasluoma et al., 2018). Given that, not only seeds of different chemical compositions but also different particle solubilities are present in the atmosphere - these uncertainties in the determination of the number concentration need to be considered. A straightforward approach to assess the uncertainty of a humid sample flow is to dry the inlet flow of a CPC by, e.g., using a Silica gel dryer or Nafion dryer, which is a common method for ambient measurements. Additionally, the inlet RH should be monitored and kept below a threshold value in order to narrow down the uncertainty from the humiditydependent change in the cutoff curve in the case of a soluble seed. In the ideal case, measuring instruments are calibrated up to the maximum RH that they are exposed to.

Hygroscopicity measurements of particles in the targeted size range further improve the assessment on the uncertainty of the number concentration. The location of the measurement site is also a clear indicator of a possible enhanced contribution of hygroscopic seed particles, i.e., when the measurement site is located close to the coastline. Thereby the accuracy of the data interpretation would increase. Even without these additional measurements, the location of the
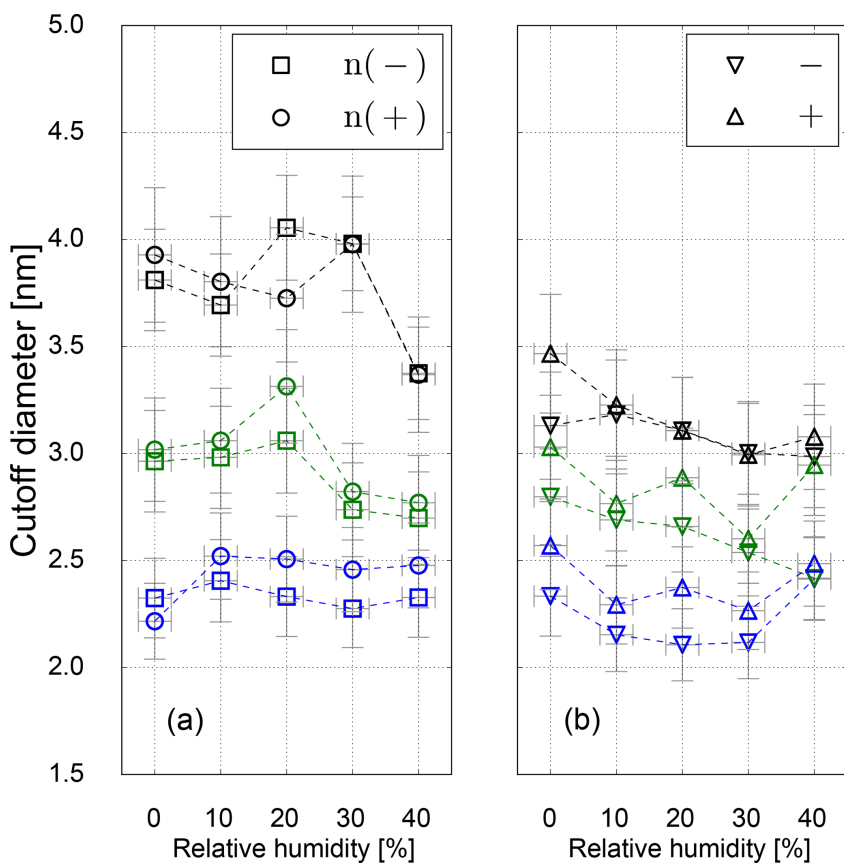

Figure 7. Cutoff diameter as a function of RH for neutral (a) and charged (b) Ag seeds for low- (blue), standard- (green) and hightemperature (black) settings.

measurement site and the source region of the seed particles can be used for data interpretation. As a result, studies that consider sea spray as a particle source should consider the effect of humidity on the particle detection efficiency. Furthermore, studies that investigate aerosol from sources that involve soluble seeds should consider the effect of humidity on the particle detection efficiency. Soluble seeds do not only include sodium chloride particles which were analyzed in this study. Ammonium sulfate, which originates from the gas phase from precursor gases having both natural and anthropogenic origin (Sakurai et al., 2005; Smith et al., 2004), can act as a soluble seed. Consequently, we suggest considering a possible shift in cutoff diameter when such soluble species are present in the sample.

Based on solubility effects and the increased polarity of the working fluid due to the addition of water molecules, similar effects using different working fluids can be assessed by interpreting their chemistry. Diethylene glycol (DEG) is a well polarized molecule due to three oxygen atoms per DEG molecule. Adding water does not increase the overall polarity as much as in the case of butanol. $\mathrm{NaCl}$ particles are soluble in DEG as well. As presented in Kangasluoma et al. (2013) variation of the inlet flow RH leads to increased detection efficiency for a turbulent mixing type CPC.

Working fluids like perfluorocarbonates (Fluorinert, FC43) consist of carbon chains with fluorine atoms instead of hydrogen atoms. These molecules have a low dipole moment. Due to the spherical structure and highly electroneg- 
ative atoms on the outside the overall surface of the molecule is slightly negatively polarized. Consequently, a shift in the cutoff diameter can be expected by using a mixture of perfluorocarbonates and water. The overall polarity of the working fluid would almost exclusively be based on the dipole moment of water molecules. Pulse height analysis measurements by Hanson et al. (2002) revealed a pronounced substance dependency and a difference in peak distribution when using $n$-butanol or FC-43 as a working fluid in a CPC. The interaction between $\mathrm{NaCl}$ seed and water molecule remains regardless of the working fluid. If RH cannot be kept at $0 \%$, the instrument should be calibrated to the corresponding conditions, and a possible change in cutoff diameter should be considered in the data analysis to ensure high data quality, especially at measurement sites located near the sea or at changing/high $\mathrm{RH}$, which is the case for most regions.

\section{Conclusions}

The presented measurements conducted with expansion and continuous flow type CPCs have shown that sodium chloride particles with a mobility diameter below $10 \mathrm{~nm}$ indicate different activation regimes. According to the SANC measurements, the required saturation ratio to activate a certain particle size is always lower for Ag particles compared to $\mathrm{NaCl}$ particles. As a consequence, the cutoff diameters measured for $\mathrm{NaCl}$ particles under dry conditions are always higher than for Ag seeds in butanol-based CPCs. Under dry conditions for particles $\leq 3 \mathrm{~nm}$ no opposite temperature trend compared to classical Kelvin predictions was observed. However, for negatively charged $\mathrm{NaCl}$ seeds a charge-enhanced activation was measured with the SANC. Above $3.5 \mathrm{~nm}$ the charge does not play a role during the nucleation process. Charge-enhanced particle activation only occurred at the lowest CPC temperature settings. We conclude that the activation of $\mathrm{NaCl}$ particles can be enhanced by increased humidity. For Ag this humidity dependence could not be observed. This is an indicator for the importance of molecular interactions between seed and vapor molecules.

A recently published study on heterogeneous nucleation of $n$-butanol on monoatomic ions has shown that the initial formation of a critical cluster does not favor one of the two possible polarities of the seed particle (Tauber et al., 2018). However, under subsaturated conditions the existence of seed particle charge plays an important role concerning vapor uptake. Hence the vapor molecules are in contact with the $\mathrm{NaCl}$ particles under subsaturated conditions before the temperature drops and can attach to the seeds. We performed measurements with $\mathrm{NaCl}$ seeds which are known to be hygroscopic. Therefore the water molecules dissociate the $\mathrm{NaCl}$ cluster and a solvation process takes place. As a consequence, the charged sodium chloride seeds attract the vapor molecules more strongly, and thereby the nucleation and condensational growth can start at smaller seed sizes. In this work we assumed that the chemical composition and charging state are the driving forces of nucleation and growth in the size range of the cutoff diameter of the used UCPC. Hence we recommend that in future studies the chemical composition of the generated particles in different charging states should be investigated.

As described by Li and Hogan Jr. (2017), the impact of vapor polarity in the measured particle size range, where interactions between single atoms are of importance, cannot be neglected. Additional water molecules increase the dipole moment of the $n$-butanol-water mixture and can change the structure of the sodium chloride cluster. If water vapor is present, charge effects on the surface promote the initial steps of nucleation even more. As a result, the energy barrier for activating nanometer-sized $\mathrm{NaCl}$ particles can be reduced - this is comparable to already published results for $n$-propanol-water mixtures conducted by Petersen et al. (2001). Our data show a strong effect of RH on heterogeneous nucleation of $n$-butanol on $\mathrm{NaCl}$ particles but not for Ag seeds. This finding suggests that the different RH sensitivity is less a consequence of binary heterogeneous nucleation but rather attributable to changing seed properties in the interaction with vapor molecules. According to the $\mathrm{NaCl}$ shrinkage measurements, a change in diameter during the presence of water vapor - which we associated with a restructural effect - could be observed.

To improve our understanding of the observed restructuring effect, future studies on heterogeneous nucleation depending on different seeds and humidity should be conducted. Also the herein presented measurements could be extended with the size selection after the particle restructuring. Additionally, higher-RH conditions could be used to investigate the restructural effect on even smaller particles. In particular, the humidity-dependent activation of hygroscopic nanoparticles which are present in the atmosphere would be of great interest. Thereby, the molecular interactions between the seed and the vapor molecules can be further evaluated, which may lead to a model description.

Our results suggest that atmospheric measurements of ambient nanoparticles should take into account possible RH effects on the instrument's cutoff diameter, when a large hygroscopic particle fraction is present. Thus, number concentration measurements should be paired with chemical and/or hygroscopicity measurements to improve the assessment of the uncertainty. If these additional measurements cannot be conducted, the location of the measurement site should be taken into account for data interpretation. Especially when conducting studies in marine surroundings, at which sea spray is one of the contributing particle sources, special care should be taken during the data evaluation (Lawler et al., 2014; Zieger et al., 2017). As a standard procedure, in many atmospheric studies the CPC inlet flow is dried before entering the instrument. We suggest that additional monitoring of the $\mathrm{RH}$ of the inlet flow is critical, since the variation in RH between $0 \%$ and $40 \%$ even shows a pronounced shift in the 
cutoff diameter. This would lead to an overestimation in the number concentration of nucleation mode particles. In ambient conditions this mode usually contains high number concentrations of particles. Comparison between measurements taken in different regions with varying hygroscopic nanoparticle concentrations thus need to be treated with care to avoid the wrong interpretation.

Data availability. Supplement data associated with this article can be found in the online version.

Supplement. The supplement related to this article is available online at: https://doi.org/10.5194/amt-12-3659-2019-supplement.

Author contributions. CT designed the setup; CT performed the SANC experiments; CT, SB and PJW performed the detection efficiency measurements; PSB and GK performed the shrinkage measurements; CT, SB, PJW, GS and PMW were involved in the scientific interpretation and discussion; and CT, SB, PJW and PMW wrote the manuscript.

Competing interests. The authors declare that they have no conflict of interest.

Acknowledgements. This work was supported by the European Research Council under the European Community's Seventh Framework Programme (FP7/2007/2013). Dimitri Castarède and Lennart Graewe are thanked for helpful discussions.

Financial support. This research has been supported by the European Research Council (grant no. 616075).

Review statement. This paper was edited by Charles Brock and reviewed by three anonymous referees.

\section{References}

Alonso, M. and Alguacil, F.: Particle Size Distribution Modification During and After Electrical Charging: Comparison between a Corona Ionizer and a Radioactive Neutralizer, Aerosol Air Qual. Res., 8, 366-380, https://doi.org/10.4209/aaqr.2008.07.0029, 2008.

Ankilov, A., Baklanov, A., Colhoun, M., Enderle, K.-H., Gras, J., Julanov, Y., Kaller, D., Lindner, A., Lushnikov, A., Mavliev, R., McGovern, F., O'Connor, T., Podzimek, J., Preining, O., Reischl, G., Rudolf, R., Sem, G., Szymanski, W., Vrtala, A., Wagner, P., Winklmayr, W., and Zagaynov, V.: Particle size dependent response of aerosol counters, Atmos. Res., 62, 209-237, https://doi.org/10.1016/S0169-8095(02)00011-X, 2002.
Barmpounis, K., Ranjithkumar, A., Schmidt-Ott, A., Attoui, M., and Biskos, G.: Enhancing the detection efficiency of condensation particle counters for sub-2 nm particles, J. Aerosol Sci., 117, 4453, https://doi.org/10.1016/j.jaerosci.2017.12.005, 2018.

Biskos, G., Malinowski, A., Russell, L. M., Buseck, P. R., and Martin, S. T.: Nanosize Effect on the Deliquescence and the Efflorescence of Sodium Chloride Particles, Aerosol Sci. Technol., 40, 97-106, https://doi.org/10.1080/02786820500484396, 2006.

Castarède, D. and Thomson, E. S.: A thermodynamic description for the hygroscopic growth of atmospheric aerosol particles, Atmos. Chem. Phys., 18, 14939-14948, https://doi.org/10.5194/acp-18-14939-2018, 2018.

Chen, C.-C. and Tao, C.-J.: Condensation of supersaturated water vapor on submicrometer particles of $\mathrm{SiO} 2$ and $\mathrm{TiO} 2$, J. Chem. Phys., 112, 9967-9977, https://doi.org/10.1063/1.481633, 2000.

Chen, H., Chee, S., Lawler, M. J., Barsanti, K. C., Wong, B. M., and Smith, J. N.: Size resolved chemical composition of nanoparticles from reactions of sulfuric acid with ammonia and dimethylamine, Aerosol Sci. Technol., 52, 1120-1133, https://doi.org/10.1080/02786826.2018.1490005, 2018.

Clarke, A., Kapustin, V., Howell, S., Moore, K., Lienert, B., Masonis, S., Anderson, T., and Covert, D.: SeaSalt Size Distributions from Breaking Waves: Implications for Marine Aerosol Production and Optical Extinction Measurements during SEAS, J. Atmos. Ocean. Tech., 20, 1362-1374, https://doi.org/10.1175/15200426(2003)020<1362:SSDFBW>2.0.CO;2, 2003.

Ferreiro, J. J., Chakrabarty, S., Schläppi, B., and Signorell, R.: Observation of propane cluster size distributions during nucleation and growth in a Laval expansion, J. Chem. Phys., 145, 211907, https://doi.org/10.1063/1.4960050, 2016.

Hanson, D. R., Eisele, F. L., Ball, S. M., and McMurry, P. M.: Sizing Small Sulfuric Acid Particles with an Ultrafine Particle Condensation Nucleus Counter, Aerosol Sci. Technol., 36, 554-559, https://doi.org/10.1080/02786820252883793, 2002.

Iida, K., Stolzenburg, M. R., and McMurry, P. H.: Effect of Working Fluid on Sub-2 nm Particle Detection with a Laminar Flow Ultrafine Condensation Particle Counter, Aerosol Sci. Technol., 43, 81-96, https://doi.org/10.1080/02786820802488194, 2009.

IPCC: Summary for Policymakers, book section SPM, pp. 1-30, Cambridge University Press, Cambridge, United Kingdom and New York, NY, USA, https://doi.org/10.1017/CBO9781107415324.004, 2013.

Kangasluoma, J., Junninen, H., Lehtipalo, K., Mikkilä, J., Vanhanen, J., Attoui, M., Sipilä, M., Worsnop, D., Kulmala, M., and Petäjä, T.: Remarks on Ion Generation for CPC Detection Efficiency Studies in Sub-3-nm Size Range, Aerosol Sci. Technol., 47, 556-563, https://doi.org/10.1080/02786826.2013.773393, 2013.

Kangasluoma, J., Samodurov, A., Attoui, M., Franchin, A., Junninen, H., Korhonen, F., Kurtén, T., Vehkamäki, H., Sipilä, M., Lehtipalo, K., Worsnop, D. R., Petäjä, T., and Kulmala, M. Heterogeneous Nucleation onto Ions and Neutralized Ions: Insights into Sign-Preference, J. Phys. Chem. C, 120, 7444-7450, https://doi.org/10.1021/acs.jpcc.6b01779, 2016.

Kangasluoma, J., Ahonen, L. R., Laurila, T. M., Cai, R., Enroth, J., Mazon, S. B., Korhonen, F., Aalto, P. P., Kulmala, M., Attoui, M., and Petäjä, T.: Laboratory verification of a new high flow differential mobility particle sizer, and 
field measurements in Hyytiälä, J. Aerosol Sci., 124, 1-9, https://doi.org/10.1016/j.jaerosci.2018.06.009, 2018.

Krämer, L., Pöschl, U., and Niessner, R.: Microstructural rearrangement of sodium chloride condensation aerosol particles on interaction with water vapor, J. Aerosol Sci., 31, 673-685, https://doi.org/10.1016/S0021-8502(99)00551-0, 2000.

Kuang, C., Riipinen, I., Sihto, S.-L., Kulmala, M., McCormick, A. V., and McMurry, P. H.: An improved criterion for new particle formation in diverse atmospheric environments, Atmos. Chem. Phys., 10, 8469-8480, https://doi.org/10.5194/acp-108469-2010, 2010.

Kuang, C., Chen, M., Zhao, J., Smith, J., McMurry, P. H., and Wang, J.: Size and time-resolved growth rate measurements of 1 to $5 \mathrm{~nm}$ freshly formed atmospheric nuclei, Atmos. Chem. Phys., 12, 3573-3589, https://doi.org/10.5194/acp-12-3573-2012, 2012.

Kulmala, M., Lauri, A., Vehkamäki, H., Laaksonen, A., Petersen, D., and Wagner, P. E.: Strange Predictions by Binary Heterogeneous Nucleation Theory Compared with a Quantitative Experiment, J. Phys. Chem. B, 105, 11800-11808, https://doi.org/10.1021/jp011740c, 2001.

Kulmala, M., Laakso, L., Lehtinen, K. E. J., Riipinen, I., Dal Maso, M., Anttila, T., Kerminen, V.-M., Hõrrak, U., Vana, M., and Tammet, H.: Initial steps of aerosol growth, Atmos. Chem. Phys., 4, 2553-2560, https://doi.org/10.5194/acp-4-2553-2004, 2004.

Kulmala, M., Petäjä, T., Ehn, M., Thornton, J., Sipilä, M., Worsnop, D., and Kerminen, V.-M.: Chemistry of Atmospheric Nucleation: On the Recent Advances on Precursor Characterization and Atmospheric Cluster Composition in Connection with Atmospheric New Particle Formation, Annu. Rev. Phys. Chem., 65, 21-37, https://doi.org/10.1146/annurev-physchem-040412110014, 2014.

Kupc, A., Winkler, P. M., Vrtala, A., and Wagner, P.: Unusual Temperature Dependence of Heterogeneous Nucleation of Water Vapor on Ag Particles, Aerosol Sci. Technol., 47, i-iv, https://doi.org/10.1080/02786826.2013.810330, 2013.

Lawler, M. J., Whitehead, J., O’Dowd, C., Monahan, C., McFiggans, G., and Smith, J. N.: Composition of 15-85 nm particles in marine air, Atmos. Chem. Phys., 14, 11557-11569, https://doi.org/10.5194/acp-14-11557-2014, 2014.

Li, C. and Hogan Jr., C. J.: Vapor specific extents of uptake by nanometer scale charged particles, Aerosol Sci. Technol., 51, 653-664, https://doi.org/10.1080/02786826.2017.1288285, 2017.

Loudon, M. G.: Organic Chemistry, 5 edn., Roberts and Company Publishers, Greenwood Village Colorado, 2009.

Martin, S. T.: Phase Transitions of Aqueous Atmospheric Particles, Chem. Rev., 100, 3403-3454, https://doi.org/10.1021/cr990034t, 2000.

McGraw, R., Wang, J., and Kuang, C.: Kinetics of Heterogeneous Nucleation in Supersaturated Vapor: Fundamental Limits to Neutral Particle Detection Revisited, Aerosol Sci. Technol., 46, 1053-1064, https://doi.org/10.1080/02786826.2012.687844, 2012.

McGraw, R. L., Winkler, P. M., and Wagner, P. E.: Temperature Dependence in Heterogeneous Nucleation with Application to the Direct Determination of Cluster Energy on Nearly Molecular Scale, Sci. Rep., 7, 2045-2322, https://doi.org/10.1038/s41598017-16692-9, 2017.
McMurry, P. H.: A review of atmospheric aerosol measurements, Atmos. Environ., 34, 1959-1999, https://doi.org/10.1016/S13522310(99)00455-0, 2000.

McMurry, P. H., Fink, M., Sakurai, H., Stolzenburg, M. R., Mauldin III, R. L., Smith, J., Eisele, F., Moore, K., Sjostedt, S., Tanner, D., Huey, L. G., Nowak, J. B., Edgerton, E., and Voisin, D.: A criterion for new particle formation in the sulfurrich Atlanta atmosphere, J. Geophys. Res.-Atmos., 110, D22S02, https://doi.org/10.1029/2005JD005901, 2005.

Merikanto, J., Spracklen, D. V., Mann, G. W., Pickering, S. J., and Carslaw, K. S.: Impact of nucleation on global CCN, Atmos. Chem. Phys., 9, 8601-8616, https://doi.org/10.5194/acp-9-86012009, 2009.

Petersen, D., Ortner, R., Vrtala, A., Wagner, P. E., Kulmala, M., and Laaksonen, A.: Soluble-Insoluble Transition in Binary Heterogeneous Nucleation, Phys. Rev. Lett., 87, 225703, https://doi.org/10.1103/PhysRevLett.87.225703, 2001.

Reichardt, C. and Welton, T.: Solvents and Solvent Effects in Organic Chemistry, 4 edn., Wiley-VCH Verlag GmbH \& Co. KGaA, Weinheim, 2011.

Sakurai, H., Fink, M. A., McMurry, P. H., Mauldin, L., Moore, K. F., Smith, J. N., and Eisele, F. L.: Hygroscopicity and volatility of 4-10 nm particles during summertime atmospheric nucleation events in urban Atlanta, J. Geophys. Res.-Atmos., 110, D22S02, https://doi.org/10.1029/2005JD005918, 2005.

Scheibel, H. and Porstendörfer, J.: Generation of monodisperse $\mathrm{Ag}$ - and $\mathrm{NaCl}$-aerosols with particle diameters between 2 and $300 \mathrm{~nm}$, J. Aerosol Sci., 14, 113-126, https://doi.org/10.1016/0021-8502(83)90035-6, 1983.

Schobesberger, S., Winkler, P. M., Pinterich, T., Vrtala, A., Kulmala, M., and Wagner, P. E.: Experiments on the Temperature Dependence of Heterogeneous Nucleation on Nanometer-Sized $\mathrm{NaCl}$ and Ag Particles, Chem. Phys. Chem., 11, 3874-3882, https://doi.org/10.1002/cphc.201000417, 2010.

Sem, G. J.: Design and performance characteristics of three continuous-flow condensation particle counters: a summary, Atmos. Res., 62, 267-294, https://doi.org/10.1016/S01698095(02)00014-5, 2002.

Smith, J. N., Moore, K. F., McMurry, P. H., and Eisele, F. L.: Atmospheric Measurements of Sub-20 nm Diameter Particle Chemical Composition by Thermal Desorption Chemical Ionization Mass Spectrometry, Aerosol Sci. Technol., 38, 100-110, https://doi.org/10.1080/02786820490249036, 2004.

Spracklen, D. V., Carslaw, K. S., Kulmala, M., Kerminen, V.-M., Sihto, S.-L., Riipinen, I., Merikanto, J., Mann, G. W., Chipperfield, M. P., Wiedensohler, A., Birmili, W., and Lihavainen, H.: Contribution of particle formation to global cloud condensation nuclei concentrations, Geophys. Res. Lett., 35, 106808, https://doi.org/10.1029/2007GL033038, 2008.

Strey, R., Wagner, P. E., and Schmeling, T.: Homogeneous nucleation rates for $n$-alcohol vapors measured in a twopiston expansion chamber, J. Chem. Phys., 84, 2325-2335, https://doi.org/10.1063/1.450396, 1986.

Tauber, C., Chen, X., Wagner, P. E., Winkler, P. M., Hogan, C. J., and Maisser, A.: Heterogeneous Nucleation onto Monoatomic Ions: Support for the KelvinThomson Theory, Chem. Phys. Chem., 19, 3144-3149, https://doi.org/10.1002/cphc.201800698, 2018. 
Tauber, C., Steiner, G., and Winkler, P. M.: Counting efficiency determination from quantitative intercomparison between expansion and laminar flow type condensation particle counter, Aerosol Sci. Technol., 53, 344-354, https://doi.org/10.1080/02786826.2019.1568382, 2019.

Thomson, S. W.: On the equilibrium of vapour at a curved surface of liquid, Philosoph. Mag., 42, 448-452, 1871.

Wagner, P.: A constant-angle mie scattering method (cams) for investigation of particle formation processes, J. Colloid Interf. Sci., 105, 456-467, https://doi.org/10.1016/0021-9797(85)90319-4, 1985.

Wagner, P. E., Kaller, D., Vrtala, A., Lauri, A., Kulmala, M., and Laaksonen, A.: Nucleation probability in binary heterogeneous nucleation of water n-propanol vapor mixtures on insoluble and soluble nanoparticles, Phys. Rev. E, 67, 021605, https://doi.org/10.1103/PhysRevE.67.021605, 2003.

Wang, J., McGraw, R. L., and Kuang, C.: Growth of atmospheric nano-particles by heterogeneous nucleation of organic vapor, Atmos. Chem. Phys., 13, 6523-6531, https://doi.org/10.5194/acp13-6523-2013, 2013.

Wiedensohler, A., Orsini, D., Covert, D. S., Coffmann, D., Cantrell, W., Havlicek, M., Brechtel, F. J., Russell, L. M., Weber, R. J., Gras, J., Hudson, J. G., and Litchy, M.: Intercomparison Study of the Size-Dependent Counting Efficiency of 26 Condensation Particle Counters, Aerosol Sci. Technol., 27, 224-242, https://doi.org/10.1080/02786829708965469, 1997.
Winkler, P. M., Hienola, A., Steiner, G., Hill, G., Vrtala, A., Reischl, G. P., Kulmala, M., and Wagner, P. E.: Effects of seed particle size and composition on heterogeneous nucleation of n-nonane, Atmos. Res., 90, 187-194, https://doi.org/10.1016/j.atmosres.2008.02.001, 2008a.

Winkler, P. M., Steiner, G., Vrtala, A., Vehkamäki, H., Noppel, M., Lehtinen, K. E. J., Reischl, G. P., Wagner, P. E., and Kulmala, M.: Heterogeneous Nucleation Experiments Bridging the Scale from Molecular Ion Clusters to Nanoparticles, Science, 319, 13741377, https://doi.org/10.1126/science.1149034, 2008b.

Winkler, P. M., McGraw, R. L., Bauer, P. S., Rentenberger, C., and Wagner, P. E.: Direct determination of three-phase contact line properties on nearly molecular scale, Sci. Rep., 6, 26111, https://doi.org/10.1038/srep26111, 2016.

Wlasits, P. J.: On the Effect of Relative Humidity on the Activation of Aerosol Particles in Butanol-Based Particle Counters, Master's thesis, University of Vienna, 2019.

Zieger, P., Väisänen, O., Corbin, J. C., Partridge, D. G., Bastelberger, S., Mousavi-Fard, M., Rosati, B., Gysel, M., Krieger, U. K., Leck, C., Nenes, A., Riipinen, I., Virtanen, A., and Salter, M. E.: Revising the hygroscopicity of inorganic sea salt particles, Nat. Commun., 8, 15883, https://doi.org/10.1038/ncomms 15883 , 2017. 